\title{
Innovative Social Entrepreneurship: Development of Youth Social Activity
}

\author{
Alevtina Starshinova \\ Ural Federal University \\ Yekaterinburg, \\ Russia \\ E-mail: a.v.starshinova@urfu.ru \\ Svetlana Pankova \\ Ural Federal University \\ Yekaterinburg, \\ Russia \\ E-mail: s.n.pankova@urfu.ru
}

\author{
Eugenia Chikova \\ Ural Federal University \\ Yekaterinburg, \\ Russia \\ E-mail: pargelia@yandex.ru \\ Ludmila Lesina \\ Ural Federal University \\ Yekaterinburg, \\ Russia \\ E-mail: 1lesina@yandex.ru
}

\author{
Denis Shkurin \\ Ural Federal University \\ Yekaterinburg, \\ Russia \\ E-mail: d.v.shkurin@urfu.ru
}

\begin{abstract}
The aim of the work is to study the accelerators of social initiatives as a specific social environment and the practice of experimental testing and development of innovative social entrepreneurship of youth. The orientation of the individual towards social entrepreneurship and the development of readiness for it can only partially be explained through the prospects of a future career. In many ways, entrepreneurship is a way of personal development, empathy, social creativity. Social entrepreneurship is a form of social innovation activity that goes beyond the usual norms, which requires appropriate conditions. The created terms should take into account the current specifics of the young generation and the factors affecting the development of its social potential. The most important person ability of an individual is to overcome social uncertainty and create socially positive ideas as the basis of their personal and professional success.
\end{abstract}

Keywords - accelerators; social entrepreneurship; activity; youth; university

\section{INTRODUCTION}

In modern society, there is a growing need for the development of qualities of a person's ability to independently maintain their well-being for social self-organization [1]. The participation of youth in social forms of activity in the educational process can be considered as a factor in strengthening the socially active role of youth [2]. It is essential to eliminate the contradiction between the openness of opportunities for young people thanks to new technologies and, on the other hand, their pronounced passivity. There is a contradiction in the qualitative and quantitative ratios of graduates and their relevance in the labor market.

Socially oriented entrepreneurship at the university is a means of promoting the development of students' ability to create and positive motivation [3]. One of the most relevant areas is social entrepreneurship. The willingness of students to develop social projects and enterprises seems to be essential for enhancing vocational training in areas of the social and humanitarian profile and as an alternative opportunity for professional development in other areas [4]. The main task of the accelerators contributing to the development of social entrepreneurship is the selection of people who are capable of social entrepreneurship and the subsequent support of their activities. As the creation of such conditions, universities are implementing special programs, training laboratories [5]. Such programs aim to teach project management. That is, in this form, the social design differs little from classical project management. Specially organized programs facilitate the involvement of young people in entrepreneurship through the development of specialized skills and abilities [6, 7]. The projects proposed by universities are aimed at developing entrepreneurial skills and the ability to get profit from the implementation of the project. A social project is seen as a form of classic entrepreneurship aimed at financial gain. 


\section{PURPOSE}

The study investigates the influence of accelerators of social initiatives as a specific social environment and the practice of experimental testing and development of innovative social entrepreneurship of youth. This study substantiates approaches to understanding the essence of students' readiness for social entrepreneurship.

\section{RESEARCH METHOD}

The study based on an analysis of studies is related to the study of readiness for social entrepreneurship.

As a new phenomenon, social entrepreneurship assumes a different understanding in contrast to ordinary entrepreneurship. Entrepreneurship is seen primarily as a rational form of activity [8]. A feature of traditional entrepreneurship is a high degree of awareness and rationality. This is due to the fact that the task of the entrepreneur is to get the greatest amount of profit, which is connected with the ability to build the achievement of the goal most effectively. Specific social entrepreneurship can be attributed to the form of socially conscious or planned behavior [9]. But the form of the planned action in social entrepreneurship is different. The social effect of activities is more important than financial. The fundamental difference between a social entrepreneur is his active personal position and activity. It means a high degree of involvement, which manifests itself in orientation to professional development prospects or significant personal manifestations in social terms, such as empathy, a desire to help solve a social problem. Or, the specificity is manifested in the development of socially significant creative activity of the individual, the generation of creative ideas of social projects, ideas that contribute to improving social well-being. Unlike the traditional form of entrepreneurship, activity, although it may include financial success, is inseparable from personal participation. Accordingly, it involves personal involvement and more personal development.

Also, it is the presence of the specifics of social directed activity of an individual [10]. Intentions to be a social entrepreneur characterize a rather complex process, which is associated with adaptation and overcoming. Initially, this is a process involving changes not only in the project itself but also in the subject initiating it. $\mathrm{He}$ adapts in the implementation of his project and overcomes difficulties, which contributes to the formation of a successful and socially sought-after project.

Participation in social entrepreneurship contributes to the development of social orientations of an individual [11]. A sense of conscious empathy and social capital will have a positive effect on readiness for social entrepreneurship. It follows from this that there is not only a connection between social entrepreneurship and personal values, but social entrepreneurship can be considered as a tool that promotes personal development.

Social entrepreneurship involves the implementation of socially oriented social projects and activities [12]. Therefore, it is justified to prefer theories that explain the corresponding characteristics of personality and attitude. Readiness for the implementation of social entrepreneurship involves the development of positive orientation towards social entrepreneurship rather than the development of rational approaches to entrepreneurial activities [13]. The essence of personal readiness for social entrepreneurship is primarily revealed through the introduction of an explanation of the behavior of the value component [14].

The theory of self-determination can explain the formation of an independent and dominant position, but focused on the implementation of values, is adequate to socially acceptable methods of achieving goals and focus on social benefits [15]. This theory is most promising in explaining the conditions for the formation of activity in conditions of social uncertainty and explains the basics of how a person can preserve the values and social continuity of activity. The theory of selfdetermination characterizes the subjective prerequisites of activity based on values, appropriate practices of action and social resources, the ability to self-organization and selfdevelopment [1]. Projects aimed at the development of social entrepreneurship are an experimental platform in which it becomes possible to test not only different methods of activity but also values and meanings. It is a practical way with a choice that is most promising for the development of social orientations of a person [16]. The practical method allows experimentally not only to identify existing orientations and values but to a greater extent to develop them. In the absence of choice and practical ability to freely express oneself, a positive effect in the development of a personality cannot manifest itself. This is because, in the absence of choice and practical activity, the pressure of norms appears, which can control and suppress types of activity that are inappropriate to the norm, but not develop them.

Trends in the development of modern society suggest the need for leaders to be able to be effective in the new conditions conducive to economic growth, taking into account new social and economic realities $[17,18]$. For the development of the innovative activity, personal qualities are needed that contribute to the practical orientation of the activity. That is, the ability to put ideas into practice in the conditions of uncertainty - a special type of leader who is capable of searching for new non-standard ideas based on their arrival. Leaders should not only be able to offer innovative ideas but, to a greater extent, be able to overcome difficulties, be effective in the face of uncertainty and risk. In this regard, social entrepreneurship is approaching the classical form of entrepreneurship. But a social entrepreneur in his focus should be socially useful. In this regard, a unique role of social entrepreneurship appears [11]. For its successful implementation, it involves the development of personal characteristics associated with creativity, responsibility and connection with social capital.

Nevertheless, despite the content of social entrepreneurship, motivation, focus on social entrepreneurship does not always imply prosocial attitudes and may suggest material benefits [19]. The intention to carry out sociallyoriented activities is more important than the prerequisites that prompted this. Besides, the focus on the creation of social benefits does not exclude the achievement of material benefits. 
Social accelerators propose solving the problems of training specialists by creating training methods aimed at developing readiness for entrepreneurial activity [4]. Students learn the basic stages of social entrepreneurship: from creating a project idea to evaluating its effectiveness.

Ways to carry out social and entrepreneurial activities are close to the traditional form of entrepreneurship, associated with training in the most effective ways of organizing events [20]. The significant difference in readiness for social entrepreneurship can be explained through a conceptual model of socially cognitive theory, which explains the particular orientation of the participants. She describes the focus on social entrepreneurship as a career [10]. Readiness for social entrepreneurship is only partially explained by socially cognitive theory, essential components of preparation for social entrepreneurship are associated with the development of socially oriented creativity and the development of social empathy [11]. As a result of the implementation of projects, students are not only able to decide on career prospects, but also develop important personal qualities and abilities.

Social entrepreneurship is a form of social innovation activity that goes beyond the usual norms, which requires a particular social space and action. Conditions conducive to the development of social business through social projects should suggest the possibility of developing ways to implement social projects successfully [4]. Rather, they should not impose the need to carry out socially useful activities, but rather provide an opportunity to be creative in generating creative ideas concerning solving socially significant issues. At the same time, relevance should not be imposed. Creation and experience in the implementation of the project contribute to the fact that the willingness to implement the project will develop voluntarily, and this will contribute to the development and strengthening of socially-oriented values. It is important to take into account the types of individual orientations associated with the diversity of cultural orientations since various methods of activating the social and entrepreneurial activity of youth depend on them [21]. In connection with these differences, the incentive sources may be different, but more important is the intention to carry out the activity. For example, in the beginning, the project initiative may be game, experimental, but later it develops into a trajectory of professional development. If space has been formed for students to experimentally test social ideas, it is likely that some of them will begin to seek appropriate professional self-determination [22]. For another part of students, as a source of activity is the opportunity to prove themselves in socially significant and creative activities. In this case, the implementation of a social project acts as a challenge, overcoming which the young man develops himself. The possibility of creative choice, in this case, is the leading factor.

The created terms should take into account the current specifics of the young generation and the factors affecting the development of its social potential, taking into account the transforming influence of social institutions. First of all, it is the ability to overcome social uncertainty and create socially positive ideas as the basis of their personal and professional success. As the most effective conditions that stimulate the activity and development of the individual is the possibility of choice and practical experimental testing of social creative ideas in the conditions of free choice.

\section{Acknowledgment}

The article was prepared with the support of the Russian Science Foundation, project No. 19-18-00246 "Challenges of the Transformation of the Welfare State in Russia: Institutional Changes, Social Investment, Digitalisation of Social Services", which is being implemented at St. Petersburg State University.

\section{References}

[1] L. Omelchenko, "Psychological readiness of future educational managers for innovation activity", Science and Education, vol. 8, pp. 9094, 2015.

[2] N.V. Popova, E.V. Popova, "Volunteering as a factor in the formation of moral standards among young people", Obrazovanie I Nauka-Education and Science, vol. 20(10), pp. 139-155, 2018.

[3] P. Kazin, S. Hagen, A. Prichislenko, A. Zlenko, "Developing the Entrepreneurial University through Positive Psychology and Social Enterprise: A Case Study of Curriculum Innovation in Russia", Voprosy Obrazovaniya-Educational Studies Moscow, vol. 3, pp. 110-131, 2017.

[4] E.G. Syryamkina, T.B. Rumyantseva, E.Y. Liventsova, "Educational potential of the "social accelerator" technology: developing social entrepreneurial competence of students at classical universities", Obrazovanie I Nauka-Education and Science, vol. 20(1), pp. 171-187, 2018.

[5] S. Apenko, G. Chernobaeva, "Student Project Laboratory as the Ground for Realizing Innovative Business Ideas", ICIE 2016 Proceedings of the 4th International Conference on Innovation and Entrepreneurship: ICIE2016. - Academic Conferences and publishing limited, p. 30, 2016. [4th International Conference on Innovation and Entrepreneurship, p. 30, 2016].

[6] J. Greblikaite, W. Sroka, N. Gerulaitiene, "Involving Young People in Polish and Lithuanian Social Enterprises by Fostering Entrepreneurial Skills and Abilities as Entrepreneurial Opportunity at University", Entrepreneurial Business and Economics Review, vol. 4(3), pp. 131-152, 2016.

[7] O. Ocheretna, "Involving future telecommunication engineers in selfguided work during professional training as a pedagogical condition of their acmeological culture formation", Science and Education, vol. 1, pp.152-+, 2016.

[8] N.F. Krueger, M.D. Reilly, A.L. Carsrud, "Competing models of entrepreneurial intentions", Journal of Business Venturing, vol. 15(5-6), pp. 411-432, 2000.

[9] P.A.H. Aure, R.P. Dui, S.V. Jimenez, D.D. Daradar, A.N.A. Gutierrez A.C. Blasa, J. Sy-Changco, "Understanding social entrepreneurial intention through social cognitive career theory: a partial least squares structural equation modelling approach", Organizations and Markets in Emerging Economies, vol. 10(1), pp. 92-110, 2019.

[10] A.T.P. Tran, H. Von Korflesch, "A conceptual model of social entrepreneurial intention based on the social cognitive career theory", Asia Pacific Journal of Innovation and Entrepreneurship, vol. 10(1), pp. 17-38, 2016.

[11] X.E. Peng, C.Y. Liang, "Before Nonprofit Organisations Become Social Enterprises", Voluntas, vol. 30(3), pp. 460-474, 2019.

[12] D.C. Chou, "Applying design thinking method to social entrepreneurship project", Computer Standards \& Interfaces, vol. 55, pp. 73-79, 2018.

[13] W.K. Wang, Y.K. Tang, Y. Liu, T. Zheng, J. Liu, H.Y. Liu, "Can Sense of Opportunity Identification Efficacy Play a Mediating Role? Relationship Between Network Embeddedness and Social Entrepreneurial Intention of University Students", Frontiers in Psychology, vol. 10, pp. 1-13, 2019. 
[18] M.H. Fard, N.S. Amiri, M. Oboudi, S. Ramezani, "Spiritual Intelligence and Social Entrepreneurial Intentions Among Students: The Mediating Role of Entrepreneurial Passion", in: N. Faghih, M.R. Zali (Eds.), Entrepreneurship Education and Research in the Middle East and North Africa, Springer International Publishing Ag, Cham, pp. 169-191, 2018. Entrepreneurship, vol. 10(1), pp. 55-83, 2019.

[15] A. Reznickova, L. Zepeda, "Can Self-Determination Theory Explain the Self-Perpetuation of Social Innovations? A Case Study of Slow Food at the University of WisconsinMadison", Journal of Community \& Applied Social Psychology, vol. 26(1), pp. 3-17, 2016.

[16] Z.J. Yang, "Predicaments and Strategies of Moral Education and Personnel Cultivation for Private Universities", Proceedings of the 2016 International Conference on Arts, Design and Contemporary Education, vol. 64, pp. 1480-1484, 2016.

[17] V.I. Kabrin, Y.V. Smetanova, E.A. Zvezdina, "COMPARATIVE RESEARCH OF PSYCHOSEMANTICS OF BUSINESS DEVELOPMENT TENDENCIES IN THE SIBERIAN REGION IN A TRANSCULTURAL CONTEXT", Tomsk State University Journal, vol. 399, pp. 228-235, 2015.

19] E. Douglas, C. Prentice, "Innovation and profit motivations for social entrepreneurship: A fuzzy-set analysis", Journal of Business Research, vol. 99, pp. 69-79, 2019.

[20] P.N. Ghauri, M. Tasavori, R. Zaefarian, "Internationalisation of service firms through corporate social entrepreneurship and networking", International Marketing Review, vol. 31(6), pp. 576-600, 2014.

[21] S.L. Mueller, A.S. Thomas, "Culture and entrepreneurial potential: A nine country study of locus of control and innovativeness", Journal of Business Venturing, vol. 16(1), pp. 51-75, 2001.

[22] P. Tiwari, A.K. Bhat, J. Tikoria, "Predictors of social entrepreneurial intention: an empirical study", South Asian Journal of Business Studies, vol. 6(1), pp. 53-79, 2017. 